\title{
Editorial
}

\section{New KES Symposia}

\author{
Bob Howlett \\ Editor-in-Chief
}

Regular followers of KES International activities will know that it is our aim to support the intelligentsystems community by providing high-quality events and publications. Starting from relatively humble origins, KES has developed considerably in terms of quantity and quality since its inception about 10 years ago. The annual KES conference is now a well-established event in the intelligent systems calendar, and it regularly attracts around 500 delegates from above 50 countries of the world. The KES Journal is being evaluated for ISI indexing, and we are confident that we will be successful in achieving this important endorsement of the quality of the publication.

We are constantly looking for ways to provide opportunities for researchers to disseminate their results to the rest of the intelligent systems research community. While the annual KES conference does this in a general way, and has wide appeal, it is clear that there is extensive demand for high-quality events focussed on specific areas of intelligent systems.

For this reason, we have decided that in addition to the annual KES conference, we will initiate a series of conference-style events, or symposia, each with a specific topic from within the intelligent systems area. The first of these will be the KES International Symposium on Agents and Multi-Agent Systems - Technologies and Applications (KES-AMSTA-07). The aim of the symposium is to provide a high-profile, internationally respected archival forum for scientific research in the theory and practice of autonomous agents and multiagent systems. KES-AMSTA-07 is organized by KES International in cooperation with Wroclaw University of Technology, and will be held in Wroclaw, Poland, on $17^{\text {th }}$ and $18^{\text {th }}$ May 2007.

Wroclaw is the economical, cultural and intellectual capital of Lower Silesia, located in south-west Poland, $160 \mathrm{~km}$ from Germany and $120 \mathrm{~km}$ from the Czech Republic. Wroclaw is one of the oldest and most beautiful cities in Poland. Situated at the foot of the Sudety Moutains, upon the Odra River and cut through by its numerous tributaries and canals, it is an exceptional city of 12 islands and 112 bridges. The city with its charming historical centre, parks, good restaurants, hotels and friendly people (700.000 inhabitants) is easy to reach, and a pleasant place to visit for a holiday or business.

A full Call for Papers for KES-AMSTA-07 is contained later in this edition of the KES Journal.

Of course the KES2006 conference, taking place on $9^{\text {th }}-11^{\text {th }}$ October in Bournemouth, UK, is nearly upon us, and preparations are starting for KES2007, which will be in Vietri Sul Mare, near Salerno in Italy on $12^{\text {th }}-14^{\text {th }}$ September 2007. Also in the pipeline is a symposium on Intelligent Decision Technologies, which is planned for April 2008. 